\title{
Triplet schedule of weekly 5-Fluorouracil and alternating irinotecan or oxaliplatin in advanced colorectal cancer: A dose-finding and phase II study
}

\author{
M.F. MORELLI ${ }^{2 *}$, A. SANTOMAGGIO ${ }^{*}$, E. RICEVUTO ${ }^{1}$, K. CANNITA ${ }^{1}$, F. DE GALITIIS ${ }^{2}$, \\ M. TUDINI ${ }^{1}$, G. BRUERA ${ }^{1}$, M. MANCINI ${ }^{1}$, M. PELLICCIONE ${ }^{1}$, F. CALISTA $^{1}$, \\ F. GUGLIELMI ${ }^{1}$, F. MARTELLA ${ }^{1}$, P. LANFIUTI BALDI ${ }^{1}$, G. PORZIO ${ }^{1}$, A. RUSSO ${ }^{4}$,

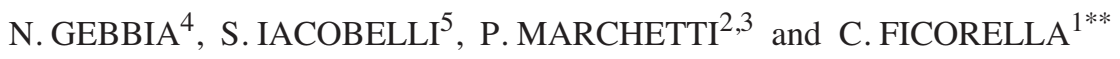

\begin{abstract}
${ }^{1}$ Medical Oncology, S. Salvatore Hospital, University of L'Aquila; ${ }^{2}$ IDI (Istituto Dermopatico dell'Immacolata) Rome;
${ }^{3}$ Medical Oncology, S. Andrea Hospital, La Sapienza University, Rome; ${ }^{4}$ Medical Oncology, University of Palermo;

${ }^{5}$ Department of Oncology and Neurosciences, 'G. D'Annunzio' University, Chieti, Italy
\end{abstract}

Received October 20, 2009; Accepted January 25, 2010

DOI: $10.3892 /$ or_00000805

\begin{abstract}
A weekly administration of alternating irinotecan or oxaliplatin associated to 5-Fluorouracil in advanced colorectal cancer was planned in order to evaluate a new schedule maintaining dose intensities of each drug as in double combinations and tolerability of the triplet association. The following weekly schedule was administered: irinotecan, days 1 and 15; oxaliplatin, days 8 and 22; 5-fluorouracil (5-FU) over 12-h (from 10:00 p.m. to 10:00 a.m.) timed flat infusion, days 1-2, 8-9, 15-16 and 22-23, every 4 weeks. Dosefinding and phase II study were planned. Thirteen patients were enrolled in the dose-finding study and 23 in the phase II study. The recommended doses of our study are: irinotecan $160 \mathrm{mg} / \mathrm{m}^{2}$; oxaliplatin $80 \mathrm{mg} / \mathrm{m}^{2} ; 5$-FU $900 \mathrm{mg} / \mathrm{m}^{2}$. The doselimiting toxicity was diarrhea (35\% of patients) but no cases of febrile neutropenia were observed. In 30 patients assessable for response two complete $(6.7 \%)$ and 18 partial $(60 \%)$ responses were observed, for an overall response rate of $66.7 \%(\alpha 0.05, \mathrm{CI} \pm 17)$. The triplet association using this weekly alternating schedule is an active and well-tolerated outpatient regimen. Surgical removal of residual disease was
\end{abstract}

Correspondence to: Dr Corrado Ficorella, Medical Oncology, Department of Experimental Medicine, University of L'Aquila, Via Vetoio, Coppito, L'Aquila 67100, Italy

E-mail: ficorella@interfree.it

*Contributed equally

** On behalf of CINBO (Consorzio Interuniversitario Nazionale per la Bio-Oncologia)

Key words: CPT-11, 5-fluorouracil, 1-OHP, advanced colorectal cancer considered in 5 patients and a radical resection was performed in 5 patients $(14 \%)$.

\section{Introduction}

Several phase I-II-III studies in metastatic colorectal cancer (CRC) patients have been reported using different schedule of triplet combinations of irinotecan (CTP-11), oxaliplatin (1-OHP) and 5-fluorouracil (5-FU), showing higher response rate than double associations of 5-FU with CPT-11 or 1-OHP. Nevertheless the triplet combinations show G3-4 diarrhea and/or febrile neutropenia as main toxic effects at the recommended dose (RD) justifying a variable reduction of dose-intensity (DI).

We previously showed that 12-h (10 p.m.-10 a.m.) timedflat-infusion (TFI) of 5-FU in combination with docetaxel in advanced breast cancer (1) and with CPT-11 in advanced CRC (2) is associated to an increased tolerability and high 5-FU/DI. The 12-h (10 p.m.-10 a.m.) TFI/FU infusion traces the 12-h circadian-timed infusion of 5-FU (10 p.m.-10 a.m. with maximum delivery at 4 a.m.) and was chosen to exploit the increased activity in the mononuclear cells of dehydropyrimidine dihydrogenase (DPD), the enzyme involved in 5-FU intracellular catabolism, and the reduced proliferation of normal target tissue, such as the bone marrow and the oral/rectal mucosa, during the night hours (3-5).

LV modulation of infusional 5-FU, alone or in combination with new drugs such as CPT-11, increases gastrointestinal toxicity without increasing clinical benefit (6-8).

Thus, a weekly administration schedule of alternating CPT-11 or 1-OHP associated to TFI/5-FU, without leucovorin (LV), was planned in order to maintain the DI of each drug on the same level of the two drugs combinations and evaluate tolerability. L-OHP was administered over 2-h as an intravenous infusion, from 3 p.m to 5 p.m., as the chronomodulated infusion of 1-OHP, peaking at 4 p.m., is less toxic than the constant-rate infusion (9). Here, we present an analysis of the safety and activity of this triplet schedule in metastatic $\mathrm{CRC}$, as first-line chemotherapy. 


\section{Treatment schedule}

\begin{tabular}{|c|c|c|c|c|c|c|c|c|}
\hline drug & d 1 & d 2 & d 8 & d 9 & d 15 & d 16 & d 22 & d 23 \\
\hline CPT-11 & $\begin{array}{c}180 \\
\mathrm{mg} / \mathrm{m}^{2}\end{array}$ & & & & $\begin{array}{c}180 \\
\mathrm{mg} / \mathrm{m}^{2}\end{array}$ & & & \\
\hline OHP & & & $\begin{array}{c}70-80 \\
\mathrm{mg} / \mathrm{m}^{2} \\
\end{array}$ & & & & $\begin{array}{c}70-80 \\
\mathrm{mg} / \mathrm{m}^{2} \\
\end{array}$ & \\
\hline $\begin{array}{c}12 \mathrm{~h} \\
5-\mathrm{FU}\end{array}$ & $\begin{array}{c}700- \\
1300 \\
\mathrm{mg} / \mathrm{m}^{2}\end{array}$ & $\begin{array}{c}700- \\
1300 \\
\mathrm{mg} / \mathrm{m}^{2}\end{array}$ & $\begin{array}{c}700- \\
1300 \\
\mathrm{mg} / \mathrm{m}^{2}\end{array}$ & $\begin{array}{c}700- \\
1300 \\
\mathrm{mg} / \mathrm{m}^{2}\end{array}$ & $\begin{array}{c}700- \\
1300 \\
\mathrm{mg} / \mathrm{m}^{2}\end{array}$ & $\begin{array}{c}700- \\
1300 \\
\mathrm{mg} / \mathrm{m}^{2}\end{array}$ & $\begin{array}{c}700- \\
1300 \\
\mathrm{mg} / \mathrm{m}^{2}\end{array}$ & $\begin{array}{c}700- \\
1300 \\
\mathrm{mg} / \mathrm{m}^{2}\end{array}$ \\
\hline & & & ery & eeks & & & & \\
\hline
\end{tabular}

Figure 1. Treatment schedule.

\section{Materials and methods}

Patient selection. All the patients fulfilled the following criteria: histologically confirmed diagnosis of CRC with clinical evidence of metastatic disease; age between 18 and 75 years; WHO performance status $\leq 2$; WBC count $\geq 4 \times 10^{3} / \mathrm{mm}^{3}$, neutrophils $\geq 2 \times 10^{3} / \mathrm{mm}^{3}$, platelets $\geq 100 \times 10^{3} / \mathrm{mm}^{3}$, hemoglobin $\geq 10 \mathrm{~g} / \mathrm{dL}$, serum creatinine $\leq 1.2 \mathrm{mg} / \mathrm{dL}$, serum bilirubin $\leq 1.5 \mathrm{mg} / \mathrm{dL}$, AST and ALT $\leq 2.5$ times normal value; life expectancy more than 3 months. Exclusion criteria included: prior chemotherapy for metastatic disease, peripheral neuropathy, uncontrolled infection, diabetes, cardiac diseases.

The study was conducted in accordance with the Helsinki declaration and the guidelines on good clinical practice. In addition, the study protocol was approved by the appropriate ethics review boards and each patient provided written consent prior to study entry.

Treatment. The following weekly schedule was administered on an outpatient basis: CPT-11, days 1 and 15; 1-OHP over 2-h as an intravenous infusion (from 3:00 p.m. to 5:00 p.m.), days 8 and 22; 5-FU over 12-h (from 10:00 p.m. to 10:00 a.m.) timed flat infusion, days 1-2, 8-9, 15-16 and 22-23, every 4 weeks. In the dose-finding study eight escalation dose levels were planned: CPT-11 $180 \mathrm{mg} / \mathrm{m}^{2}$ and 1-OHP $70 \mathrm{mg} / \mathrm{m}^{2}$ associated to 5 -FU 700,800 and $900 \mathrm{mg} / \mathrm{m}^{2} /$ day in the first 3 dose-levels, respectively; then, l-OHP was increased at 80 $\mathrm{mg} / \mathrm{m}^{2}$ and 5-FU dose-levels were increased from 900 to 1300 $\mathrm{mg} / \mathrm{m}^{2} /$ day according to a $100 \mathrm{mg} / \mathrm{m}^{2} / \mathrm{d}$ increase for each doselevel in the other 5 steps. Placement of an implanted venous access device was required. 5-FU was administered by means of a portable pump (CADD Plus, SEVIT), programmed to administer 5-FU at a given constant rate and to automatically start the infusion at 10:00 p.m. for a period of $12 \mathrm{~h}$. No prophylactic treatment with granulocyte colony-stimulating factor was used. To prevent nausea and vomiting, 5-HT3 antagonist i.v. were administered before chemotherapy and atropine $0.25 \mathrm{mg}$ was given prophylactically in order to avoid cholinergic syndrome (Fig. 1).

Dose-finding study design. The dose-escalation strategy combined the intra- and inter-patient approach (10). The accelerated design included only one patient per cohort until one patient experienced dose-limiting toxicity (DLT) or at least two patient experienced grade $(G) 2$ toxicity (except nausea or vomiting) during any course of treatment. After the initial accelerated phase, the study resorted to standard cohorts of 3 patients. If one or 2 patients experienced a DLT, a second cohort was treated at the same dose-level. If no more than two out of 6 patients experienced a DLT, the next cohort of patients was treated at the subsequent doselevel. The maximum tolerated dose (MTD) was defined as the dose at which at least $50 \%$ of the newly treated patients developed DLT.

Patients were evaluated for toxicity every week according to National Cancer Institute Common Toxicity Criteria version 2.0 (NCI-CTC). DLT included: G3 or G4 nonhematological toxicity (except nausea or vomiting), G4 neutropenia, febrile neutropenia or any other hematological G4 toxicity or any toxicity determining a treatment delay longer than 2 weeks.

Phase II study design. The phase II patients were treated at the recommended doses. The primary end points of the phase II study were the best overall response rate and the safety.

The design parameters p0 (null hypothesis) and p1 (alternative hypothesis) selected were 0.4 and 0.6 , respectively.

According to the Simon minimax two-stage design, a final sample size of 28 patients with 14 responding patients should have required to refuse the null hypothesis $(\alpha 0.10$, B0.20). The first stage of the study required 16 patients and if at least 6 objective responses were observed, the second stage required a total of 28 patients.

Tumor imaging was repeated every 3 treatment cycles (12 weeks). Tumor response was assessed and defined according 
Table I. Clinical features of patients enrolled.

Total no. $(\%)$

\begin{tabular}{|c|c|}
\hline No. of patients & 36 \\
\hline \multicolumn{2}{|l|}{ Sex } \\
\hline Male & 22 \\
\hline Female & 14 \\
\hline \multicolumn{2}{|l|}{ Age, years } \\
\hline Median & 62 \\
\hline Range & $39-74$ \\
\hline$>65$ years & $14(39)$ \\
\hline \multicolumn{2}{|l|}{ WHO performance status } \\
\hline 0 & $30(83)$ \\
\hline $1-2$ & $6(17)$ \\
\hline \multicolumn{2}{|l|}{ Primary tumor } \\
\hline Colon & $26(72)$ \\
\hline Rectum & $10(28)$ \\
\hline \multicolumn{2}{|l|}{ No. of involved sites } \\
\hline 1 & $26(72)$ \\
\hline$\geq 2$ & $10(28)$ \\
\hline \multicolumn{2}{|l|}{ Sites of metastases } \\
\hline Liver & $22(61)$ \\
\hline Lung & $8(22)$ \\
\hline Lynph nodes & $7(19)$ \\
\hline Local & $4(11)$ \\
\hline Other & $6(17)$ \\
\hline \multicolumn{2}{|l|}{ Liver metastases } \\
\hline Single & $3(8)$ \\
\hline Multiple & $19(53)$ \\
\hline Previous adjuvant chemotherapy & $9(25)$ \\
\hline FA/5-FU bolus & $6(17)$ \\
\hline 5-FU bolus + i.c. & $2(6)$ \\
\hline Irinotecan/5FU & $1(3)$ \\
\hline Previous radiotherapy & $2(6)$ \\
\hline RT alone & - \\
\hline RT+CT (5-FU i.c.) & $2(6)$ \\
\hline
\end{tabular}

WHO, World Health Organization.

to Response Evaluation Criteria in Solid Tumors (RECIST) criteria.

Patients were considered assessable for therapeutic response if they had measurable lesions and if they received more than 3 cycles.

Secondary end points were time to progression and survival. The time to disease progression and survival were assessed using the methods of Kaplan and Meier.

\section{Results}

Patients. Thirteen patients meeting eligibility criteria were enrolled in the dose-finding study and 23 in the phase II study.
A summary of patients' baseline clinical features is shown in Table I. The median age was 62 years (range 39-74); WHO performance status was 0 in 30 patients $(83 \%) ; 22(61 \%)$ had liver metastases (53\% multiple) and $9(25 \%)$ had received previous adjuvant chemotherapy with 5 -FU.

The median number of cycles administered in the dosefinding and in the phase II study was 6 (range 0.5-9).

DLT and MTD. Table II describes the observed DLTs in treated patients and cycles administered according to dose levels.

Eight escalation dose-levels were planned, but MTD was reached at the fifth dose level (5-FU DI $2000 \mathrm{mg} / \mathrm{m}^{2} /$ week; CPT-11 DI $90 \mathrm{mg} / \mathrm{m}^{2} /$ week; 1-OHP $40 \mathrm{mg} / \mathrm{m}^{2} /$ week). The first enrolled patient received the treatment according to the intra-patient dose escalation from the first to the eighth dose-level without showing G2 toxicity. The preliminary analysis of the toxicity at fifth dose-level in 5 patients (the sixth patient refused the dose-escalation), all previously treated even at lower dose levels, did not detect any DLT. In two cohorts of new patients enrolled at this dose-level DLTs were observed in 3/6 new patients: one patient experienced G3 diarrhea; one patient experienced G1 fever, requiring a 2-week delay in chemotherapy and another one G3 hypotension.

The fourth dose-level (5-FU DI $1800 \mathrm{mg} / \mathrm{m}^{2} /$ week; CPT11 DI $90 \mathrm{mg} / \mathrm{m}^{2} /$ week; 1-OHP $40 \mathrm{mg} / \mathrm{m}^{2} /$ week) represented the RD: 7 patients were treated at this dose-level (3 pretreated at lower dose-levels and 4 newly treated) for a total 12 cycles. G3 diarrhea was observed in one patient, previously treated at lower dose levels.

At the RD the G1-2 diarrhea was observed in $42 \%$ of patients and $25 \%$ of cycles; G1-2 stomatitis in $28 \%$ of patients and $25 \%$ of cycles; G1-2 nausea in $85 \%$ of patients and $58 \%$ of cycles; G1-2 neurotoxicity in $28 \%$ of patients and $33 \%$ of cycles.

Phase II toxicity and dose intensity. The most common toxic effects were diarrhea and stomatitis. Among 23 patients of phase II study, eight (35\%) had G3 diarrhea, eight (35\%) had G1-2 stomatitis (Table III), one (4\%) had G4 neutropenia, three (13\%) had G3 neutropenia, six (26\%) had G2 neutropenia and one (4\%) G3 peripheral neurotoxicity (Table IV). Although the use of G-CSF was not planned, it was used in 10/126 (8\%) of cycles and 4/23 (17\%) of patients: in 1 patient in secondary prevention after experience of G4 neutropenia, in 3 patients because persistent G2 leucopenia on the day of recycle did not permit maintaining the planned weekly schedule. One patient experienced G3 liver toxicity that required one week delay until normalization of transaminases.

One patient (4\%) experienced G4 neutropenia and no cases of febrile neutropenia were observed (Table IV). No toxic death occurred and no case of thrombosis correlated to venous access device has been registered.

In the first 18 patients enrolled in the phase II study we observed $37.5 \%$ G3 diarrhea at a median received doseintensity (rDI) of CPT-11 $70 \mathrm{mg} / \mathrm{m}^{2} /$ week (78\%). Thus, we amended the protocol at $160 \mathrm{mg} / \mathrm{m}^{2}$ irinotecan dose for the subsequent enrollment.

In the dose-finding study, 5-FU/rDI for each patient was: the median 5-FU/rDI $1667 \mathrm{mg} / \mathrm{m}^{2} / \mathrm{w}$ (range 1143-2000) 
Table II. Dose-limiting toxicities according to the dose-escalation scheme.

\begin{tabular}{|c|c|c|c|c|c|c|c|}
\hline Dose levels & $\begin{array}{c}\text { CPT11 }\left(\mathrm{mg} / \mathrm{m}^{2} \mathrm{~d} 1,15\right)- \\
\text { 1-OHP }\left(\mathrm{mg} / \mathrm{m}^{2} \mathrm{~d} 8,22\right)- \\
5-\mathrm{FU}\left(\mathrm{mg} / \mathrm{m}^{2} / \mathrm{d}\right. \\
\mathrm{d} 1-2,8-9,15-16 \\
22-23)\end{array}$ & $\begin{array}{l}\text { No. of patients }{ }^{\mathrm{a}} \\
\text { (new patients) }\end{array}$ & No. of cycles & $\begin{array}{c}\text { No. of patients } \\
\text { with } \mathrm{DLT}^{\mathrm{b}} / \text { total } \\
\text { patients }(\%)\end{array}$ & $\begin{array}{l}\text { No. of new patients } \\
\text { with DLT/new } \\
\text { patients }(\%)\end{array}$ & $\begin{array}{c}\text { No. of cycles with } \\
\text { DLT/total cycles } \\
(\%)\end{array}$ & DLTs \\
\hline I & $180-70-700$ & $2(2)$ & 2 & - & - & - & - \\
\hline II & $180-70-800$ & $3(1)$ & 3 & - & - & - & - \\
\hline III & $180-70-900$ & $3(0)$ & 3 & - & - & - & - \\
\hline IV & $180-80-900$ & $7(4)$ & 12 & 1/7 (14) & - & $1(8)$ & G3 Diarrhea \\
\hline V & $180-80-1000$ & $11(6)$ & 30 & $3 / 11(27)$ & $3 / 6(50)$ & $3(10)$ & $\begin{array}{l}\text { G3 Diarrhea } \\
\text { G1 Fever with } \\
\text { delay }>2 \text { weeks } \\
\text { G3 Hypotension }\end{array}$ \\
\hline
\end{tabular}

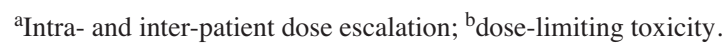

Table III. Non-haematological toxicity of phase II study.

\begin{tabular}{|c|c|c|c|c|c|c|c|c|}
\hline \multirow[b]{2}{*}{ Adverse events } & \multicolumn{4}{|c|}{ NCI-CTC grade $(\%)$ per cycles } & \multicolumn{4}{|c|}{ NCI-CTC grade $(\%)$ per patients } \\
\hline & 1 & 2 & 3 & 4 & 1 & 2 & 3 & 4 \\
\hline Nausea & $30(24)$ & $12(9.5)$ & - & - & $10(43)$ & $6(26)$ & - & - \\
\hline Vomiting & $13(10)$ & $11(9)$ & - & - & $7(30)$ & $6(26)$ & - & - \\
\hline Diarrhea & $18(14)$ & $18(14)$ & $11(9)$ & - & $3(13)$ & $8(35)$ & $8(35)$ & - \\
\hline Stomatitis & $16(13)$ & $1(1)$ & - & - & $6(26)$ & $2(9)$ & - & - \\
\hline Asthenia & $33(26)$ & $16(13)$ & $1(1)$ & - & $9(39)$ & $9(39)$ & $1(4)$ & - \\
\hline Neurotoxicity & $54(43)$ & $6(5)$ & $1(1)$ & - & $14(61)$ & $2(9)$ & $1(4)$ & - \\
\hline
\end{tabular}

NCI-CTC, National Cancer Institute Common Toxicity Criteria.

and the average $1606 \mathrm{mg} / \mathrm{m}^{2} / \mathrm{w}(\alpha 0.05, \mathrm{CI} \pm 149)$. In the phase II study $5-\mathrm{FU} / \mathrm{rDI}$ for each patient were: the median $5-\mathrm{FU} / \mathrm{rDI} 1476 \mathrm{mg} / \mathrm{m}^{2} / \mathrm{W}$ (range 900-1800) and the average $\mathrm{rDI} 1407 \mathrm{mg} / \mathrm{m}^{2} / \mathrm{w}(\alpha 0.05, \mathrm{CI} \pm 94)$.

The received dose-intensity of 5 -FU for patients was $82 \%$ of planned DI, $87.5 \%$ of $1-\mathrm{OHP}$ and $82 \%$ of CPT-11.

Antitumor activity. For the evaluation of activity, data from the 13 patients enrolled in the dose-finding study were considered together with data of the 23 patients enrolled in the phase II study and treated at the recommended dose, since the average dose intensity received by the two groups were quite similar.

Of the 33 patients included in the intent-to-treat population, 30 patients were protocol-qualified. Reasons for failure to satisfy protocol criteria included: not measurable disease in 2 patients enrolled in phase I study and one patient was lost to follow-up ( 3 patients had not received at least 3 cycles of treatment).

In the intent-to-treat analysis we observed $2 / 33$ complete responses and 21/33 partial responses with an overall response rate of $69.6 \% \alpha 0.05, \mathrm{CI} \pm 16)$. In 30 patients considered assessable for response (as treated), two complete (6.7\%) and 18 partial $(60 \%)$ responses were observed, for an overall response rate of $66.7 \%(\alpha 0.05, \mathrm{CI} \pm 17)$. We observed 3 stable disease $(10 \%)$ for a disease control rate of $76.7 \%$. Response data are summarized in Table V. Surgical removal of residual disease was considered in 5 patients and a radical resection (R0) was performed in 5 patients (all liver resections).

At 19 months of median follow-up, 23 deaths were observed $(64 \%)$. The median time to progression was 12 months (range $3+-61+$ ). The median overall survival was 20 months (range $3+-61+$ ).

\section{Discussion}

Our data propose the weekly 5-FU/TFI, without LV, in association with alternating CPT-11/1-OHP characterized by rDIs for each single drug equivalent to that proposed in schedules of double associations (5-FU/CPT-11; 5-FU/1-OHP).

The recommended doses of our study are: CPT-11 at the dose of $160 \mathrm{mg} / \mathrm{m}^{2}$, days 1 and 15; 1-OHP over 2-h infusion from 03:00 p.m to 05:00 p.m. at the dose of $80 \mathrm{mg} / \mathrm{m}^{2}$, days 8 
Table IV. Haematological toxicity of phase II study.

\begin{tabular}{|c|c|c|c|c|c|c|c|c|}
\hline \multirow[b]{2}{*}{ Adverse events } & \multicolumn{4}{|c|}{ NCI-CTC grade $(\%)$ per cycles } & \multicolumn{4}{|c|}{ NCI-CTC grade $(\%)$ per patients } \\
\hline & 1 & 2 & 3 & 4 & 1 & 2 & 3 & 4 \\
\hline Anemia & $13(10)$ & $3(2)$ & - & - & $5(22)$ & $3(13)$ & - & - \\
\hline Leucopenia & $19(15)$ & $17(13)$ & - & - & $3(13)$ & $8(35)$ & - & $1(4)$ \\
\hline Neutropenia & $10(8)$ & $21(17)$ & $7(5.5)$ & $1(1)$ & $3(13)$ & $6(26)$ & $3(13)$ & $1(4)$ \\
\hline Thrombocytopenia & $10(8)$ & $4(3)$ & - & - & $3(13)$ & $3(13)$ & - & - \\
\hline
\end{tabular}

NCI-CTC, National Cancer Institute Common Toxicity Criteria.

Table V. Objective tumor response.

\begin{tabular}{lcc}
\hline & $\begin{array}{c}\text { Assessable } \\
\text { patients (\%) }\end{array}$ & $\begin{array}{c}\text { Intention to treat } \\
\text { analysis (\%) }\end{array}$ \\
\hline No. of patients & 30 & 33 \\
CR & $2(6.7)$ & $2(6)$ \\
PR & $18(60)$ & $21(63.6)$ \\
SD & $3(10)$ & $3(9)$ \\
PD & $7(23.3)$ & $7(21.2)$ \\
\hline
\end{tabular}

$\mathrm{CR}$, complete response; $\mathrm{PR}$, partial response; $\mathrm{SD}$, stable disease; $\mathrm{PD}$, progressive disease.

and $22 ; 5-F U$ over 12-h (from 10:00 p.m. to 10:00 a.m.) timed flat infusion at a dose of $900 \mathrm{mg} / \mathrm{m}^{2}$, days $1-2,8-9$, 15-16 and 22-23, every 4 weeks. The 12-h infusion of 5-FU is more easily administered in comparison with a chronomodulated infusion and demonstrates an high antitumor activity and a tolerable toxic profile.

The relative dose-intensity of our schedule ranged between 82 and $87.5 \%$ of planned dose (CPT-11/DI 70; OHP/DI 35; 5 -FU/DI $1476 \mathrm{mg} / \mathrm{m}^{2} /$ week) and was characterized by G3 diarrhea in $35 \%$ of patients, G4 neutropenia in one patient (4\% of patients) and no febrile neutropenia.

The phase I-II studies of triplet associations in advanced CRC, using different infusion of 5-FU and different DIs of the three drugs, showed mainly severe diarrhea (range $2-72.2 \%$ ) and/or febrile neutropenia (range 1-25\%) at recommended doses (11-32).

Most of these studies included LV. In our previous doublet study we proposed a schedule excluding leucovorin $(1,2)$. Cals et al recommend a tolerable, weekly alternating schedule characterized by higher 5-FU/DI $\left(2.4 \mathrm{~g} / \mathrm{m}^{2} / \mathrm{w}, 24-\mathrm{h}\right.$ infusion) without LV, equivalent l-OHP (DI $32 \mathrm{mg} / \mathrm{m}^{2} / \mathrm{w}$ ) but lower $(<50 \%)$ CPT-11/DI $\left(40 \mathrm{mg} / \mathrm{m}^{2} / \mathrm{w}\right)$ than the present study (17). The phase I-II study by Seium et al propose a regimen with very high efficacy (the response rate was 78\%) but two febrile neutropenia episodes (one fatal) and diarrhea (23\% of patients; $3 \%$ of grade 4 ) were recorded (23).

The most active phase II studies were the following: Ychou et al (16) reported a triplet combination according to the De Gramont infusion of 5-FU with G3-4 diarrhea in $29.4 \%$ and febrile neutropenia in $3 \%$ of patients, respectively and the response rate (RR) was $70.6 \%$ (31); Calvo et al reported G3-4 diarrhea in $34.5 \%$ of patients and the overall RR was $69.2 \%$ (13). The most tolerable phase II study, as firstline advanced chemotherapy, was proposed by Ferrari et al, but the antitumor activity of triplet combination with bolus 5-FU was lower (RR 50\%) (26).

The relative dose-intensity of schedule recommended by Falcone et al ranged between 82 and $87 \%$ of planned dose (CPT-11/DI 82.5; OHP/DI 42.5; 5-FU/DI $1600 \mathrm{mg} / \mathrm{m}^{2} /$ week) and was characterized by G3-4 diarrhea, G4 neutropenia and febrile neutropenia in 20,17 and 5\% of patients, respectively. The response rate confirmed by external panel was $60 \%$ and in particular $15 \%$ of patients underwent to radical surgery in the FOLFOXIRI arm (34).

This triplet regimen is an active (RR 66.7\%) and usually well-tolerated outpatient regimen. Surgical removal of residual disease was considered in 5 patients and a radical resection (R0) was performed in 5 patients (14\%).

Present data show that the triplet combination in ACC may be administered according to a weekly alternating administration without leucovorin. This schedule is equally effective as the schedules showing higher activity and shows better tolerability concerning neutropenia.

It also shows almost equivalent activity as doublet combinations adding Bevacizumab or Cetuximab. Ongoing studies are exploring the possibility of adding antitargets to the triplet schedules in advanced colorectal cancer.

\section{References}

1. Ficorella C, Morelli MF, Ricevuto E, Cannita K, Porzio G, Baldi PL, Cianci G, DI Rocco ZC, Natoli C, Tinari N, DE Galitiis F, Calista F and Marchetti P: Timed flat infusion of 5-fluorouracil increases the tolerability of 5-fluorouracil/ docetaxel regimen in metastatic breast cancer: a dose-finding study. Br J Cancer 91: 618-620, 2004.

2. Ficorella C, Ricevuto E, Morelli MF, Morese R, Cannita K, Cianci G, Porzio G, Di Rocco ZC, De Galitiis F, De Tursi M, Tinari N, Iacobelli S and Marchetti P: Increased tolerability of bimonthly 12-hour timed flat infusion 5 -fluorouracil/irinotecan regimen in advanced colorectal cancer: a dose-finding study. Oncol Rep 15: 1345-1350, 2006.

3. Lévi F: Chronopharmacology of anticancer agents. In: Handbook of Exeperimental Pharmacology: Physiology and Pharmacology of Biological Rhythms - cancer Chemotherapy. P.H. Redfern and B. Lemmer (eds). Springer-Verlag, Berlin pp299-301, 1997.

4. Harris BE, Song R, Soong SJ and Diasio RB: Relationship between dihydropyrimidine dehidrogenase activity and plasma 5 -fluorouracil levels with evidence for circadian varation of enzyme activity and plasma drug levels in cancer patients receiving 5-fluorouracil by protracted continuous infusion. Cancer Res 50: 197-201, 1990. 
5. Smaaland R, Abrahamsen JF, Svardal AM, et al: DNA cell cycle distrubution and glutathione (GSH) content according to circadian stage in bone marrow of cancer patients. $\mathrm{Br} \mathrm{J}$ Cancer 66: 39-45, 1992

6. O'Dwyer PJ, Manola J, Valone FH, et al: Fluorouracil modulation in colorectal cancer: lack of improvement with N-phosphonoacetyl-1-aspartic acid or oral leucovorin or interferon, but enhanced therapeutic index with weekly 24-hour infusion schedule-An Eastern Cooperative Oncology Group/Cancer and Leukemia Group B Study. J Clin Oncol 19: 2413-2421, 2001 .

7. Leichman CG, Fleming TR, Muggia FM, et al: A Phase II study of fluorouracil and its modulation in advanced colorectal cancer: a Southwest Oncology Group study. J Clin Oncol 13: 1303-1311, 1995

8. Schmoll H, Köhne C, Lorenz M, et al: Weekly 24-h infusion of high-dose 5-Fluorouracil with or without Folinic Acid vs bolus 5-FU/FA (NCCTG/Mayo) in advanced colorectal cancer: a randomized phase III study of the EORTC GITCCG and the AIO. Proc Am Soc Clin Oncol 10: 287, a935, 2000.

9. Levi F, Zidani R and Misset JL: Randomised multicentre trial of chronotherapy with oxaliplatin, fluorouracil, and folinic acid in metastatic colorectal cancer. International Organization for Cancer Chronotherapy. Lancet 350: 681-686, 1997.

10. Simon R, Freidlin B, Rubinstein L, Arbuck SG, Collins J and Christian MC: Accelerated titration designs for phase I clinical trials in oncology. J Natl Cancer Inst 89: 1138-1147, 1997.

11. Bècourarn Y, Gamelin E, Coudert B, et al: Randomized multicenter phase II study comparing a combination of fluorouracil and folinic acid and alternating irinotecan and oxaliplatin with oxaliplatin and irinotecan in fluorouracil pretreated metastatic colorectal cancer patients. J Clin Oncol 19: 4195-4201, 2001.

12. Souglakos J, Mavroudis D, Kakolyris S, et al: Triplet combination with irinotecan plus oxaliplatin plus continuous-infusion fluorouracil and leucovorin as first-line treatment in metastatic colorectal cancer: a multicenter phase II trial. J Clin Oncol 20: 2651-2657, 2002.

13. Calvo E, Cortes J, Rodriguez J, et al: Irinotecan, oxaliplatin, and 5-fluorouracil/leucovorin combination chemotherapy in advanced colorectal carcinoma: a phase II study. Clin Colorectal Cancer 2: 104-110, 2002

14. Goetz MP, Erlichman C, Windebank AJ, Reid JM, Sloan JA, Atherton P, Adjei AA, Rubin J, Pitot H, Galanis E, Ames MM and Goldberg RM: Phase I and pharmacokinetic study of two different schedules of oxaliplatin, irinotecan, fluorouracil, and leucovorin in patients with solid tumors. J Clin Oncol 21: 3761-3769, 2003

15. Garufi C, Bria E, Vanni B, et al: A phase II study of irinotecan plus chronomodulated oxaliplatin, 5-fluorouracil and folinic acid in advanced colorectal cancer patients. Br J Cancer 89: 1870-1875, 2003

16. Ychou M, Conroy T, Seitz JF, Gourgou S, Hua A, MeryMignard D and Kramar A: An open phase I study assessing the feasibility of the triple combination: oxaliplatin plus irinotecan plus leucovorin/ 5-fluorouracil every 2 weeks in patients with advanced solid tumors. Ann Oncol 14: 481-489, 2003.

17. Cals L, Rixe O, Francois E, Favre R, Merad L, Deplanque G, Laadem A, Juin P, Bereder JM, Bernardini D and Herait P: Dose-finding study of weekly 24-h continuous infusion of 5fluorouracil associated with alternating oxaliplatin or irinotecan in advanced colorectal cancer patients. Ann Oncol 15: 1018-1024, 2004.

18. Masi G, Allegrini G, Cupini S, et al: First-line treatment of metastatic colorectal cancer with irinotecan, oxaliplatin and 5-fluorouracil/leucovorin (FOLFOXIRI): results of a phase II study with a simplified biweekly schedule. Ann Oncol 15: 1766-1772, 2004.

19. Gil-Delgado MA, Bastian G, Guinet F, Spano JP, Taillibert S, Rocher MA, Castaing D, Adam R, Urien S, Bismuth $\mathrm{H}$ and Khayat D: Oxaliplatin plus irinotecan and FU-FOL combination and pharmacokinetic analysis in advanced colorectal cancer patients. Am J Clin Oncol 27: 294-298, 2004.

20. Abad A, Massuti B, Gallego J, Yuste AL, Manzano JL, Carrato A, Anton A, Marfa X and Diaz-Rubio E; Spanish Cooperative Group for Gastrointestinal Tumor Therapy: Phase I study of the combination of oxaliplatin, irinotecan and continuous infusion 5-fluorouracil in digestive tumors. Anticancer Drugs 15: 469-471, 2004
21. Rosati G, Tucci A, Rinaldi A, et al: A phase II study of irinotecan alternated with a weekly schedule of oxaliplatin, high-dose leucovorin and 48-hour infusion 5-fluorouracil in patients with advanced colorectal cancer. Oncology 66: 371-378, 2004.

22. Aparicio J, Fernandez-Martos C, Vincent JM, Maestu I, Llorca C, Busquier I, Campos JM, Perez-Enguix D and Balcells M: FO LFOX alternated with FOLFIRI as first-line chemotherapy for metastatic colorectal cancer. Clin Colorectal Cancer 5: 263-267, 2005.

23. Seium Y, Stupp R, Ruhstaller T, Gervaz P, Mentha G, Philippe M, Allal A, Trembleau C, Bauer J, Morant R and Roth AD: Oxaliplatin combined with irinotecan and 5-fluorouracil/ leucovorin (OCFL) in metastatic colorectal cancer: a phase I-II study. Ann Oncol 16: 762-766, 2005.

26. Ferrari V, Valcamonico F, Amoroso V, Simoncini E, Vassalli L, Marpicati P, Rangoni G, Grisanti S, Pasinetti N and Marini G: An alternating rEgimen of irinotecan/ 5-fluorouracil/folinic acid and oxaliplatin/ 5-fluorouracil/folinic acid in metastatic colorectal cancer: a Phase II trial. Oncology 69: 283-289, 2005.

27. Martinez J, Martin C, Chacon M, Korbenfeld E, Bella S, Senna S, Richardet E, Coppola F, Bas C, Hidalgo J, Escobar E, Reale M, Smilovich AM and Wasserman E: Irinotecan, oxaliplatin plus bolus 5-fluorouracil and low dose folinic acid every 2 weeks: a feasibility study in metastatic colorectal cancer patients. Am J Clin Oncol 29: 45-51, 2006.

28. Bonetti A, Zaninelli M, Durante E, Fraccon AP, Franceschi T, Pasini F, Zustovich F and Brienza S: Multiple-target chemotherapy (LV-modulated 5-FU bolus and continuous infusion, oxaliplatin, CPT- 11) in advanced 5-FU-refractory colorectal cancer: MTD definition and efficacy evaluation. A phase I-II study. Tumori 92: 389-395, 2006.

29. Comella P, Massidda B, Palmeri S, Putzu C, De Rosa V, Izzo F, Fiore F, Casaretti R and Sandomenico C: Biweekly oxaliplatin plus irinotecan and folinic acid-modulated 5-fluorouracil: a phase II study in pretreated patients with metastatic colo-rectal cancer. Anticancer Drugs 17: 985-992, 2006.

30. McWilliams RR, Goetz MP, Morlan BW, Salim M, Rowland KM, Krook JE, Ames MM and Erlichman C: Phase II trial of oxaliplatin/irinotecan/5-fluorouracil/leucovorin for metastatic colorectal cancer. Clin Colorectal Cancer 6: 516-521, 2007

31. Ychou M, Viret F, Kramar A, Desseigne F, Mitry E, Guimbaud R, Delpero JR, Rivoire M, Quénet F, Portier G and Nordlinger B: Tritherapy with fluorouracil/leucovorin, irinotecan and oxaliplatin (FOLFIRINOX): a phase II study in colorectal cancer patients with non-resectable liver metastases Cancer Chemother Pharmacol 62: 195-201, 2007.

32. Abad A, Massutí B, Antón A, Vega M, Yuste AL, Marcuello E, Manzano JL, Alonso V, Carrato A, Martinez-Villacampa M, Tabernero J, Aranda E, Rivera F, Díaz-Rubio E and Therapy OB: Colorectal cancer metastasis resectability after treatment with the combination of oxaliplatin, irinotecan and 5-fluorouracil. Final results of a phase II study. Acta Oncol 47: 1-7, 2007.

33. Souglakos J, Andrulakis N, Syrigos K, et al: FOLFOXIRI (folin acid, 5-fluorouracil, oxaliplatin and irinotecan) vs FOLFIRI (folin acid, 5-fluorouracil and irinotecan) as first-line treatment in metastatic colorectal cancer (MCC): a multicentre randomised phase III trial from the Hellenic Oncology Research Group (HORG). Br J Cancer 94: 798-805, 2006.

34. Falcone A, Ricci S, Brunetti I, Pfanner E, Allegrini G, Barbara C Crinò L, Benedetti G, Evangelista W, Fanchini L, Cortesi E, Picone V, Vitello S, Chiara S, Granetto C, Porcile G, Fioretto L, Orlandini C, Andreuccetti M and Masi G; Gruppo Oncologico Nord Ovest: Phase III trial of infusional fluorouracil, leucovorin, oxaliplatin, and irinotecan (FOLFOXIRI) compared with infusional fluorouracil, leucovorin, and irinotecan (FOLFIRI) as first-line treatment for metastatic colorectal cancer: the Gruppo Oncologico Nord Ovest. J Clin Oncol 25: 1670-1676, 2007. 